\title{
Leaching improvement of ceramic cores for hollow turbine blades based on additive manufacturing
}

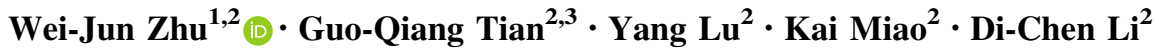

Received: 26 February 2019/Revised: 3 April 2019/Accepted: 21 July 2019/Published online: 26 September 2019

(C) The Author(s) 2019

\begin{abstract}
The precision casting method based on aluminabased ceramic cores is one of the main techniques used to manufacture hollow turbine blades. Additive manufacturing (AM) technology provides an alternate solution to fabricating ceramic cores quickly and precisely. As the complexity of the structure increases and the strength of the material improves, the leaching process of the cores becomes more complicated. This study proposes a compound pore-forming method to increase the porosity of ceramic cores by adding a preformed-pore agent and materials that convert to easy-to-corrode phases. The preformed-pore agents (e.g., carbon fibers) can be burned off during sintering to form pores before the leaching, and the easy-to-corrode phases (e.g., $\mathrm{CaCO}_{3}, \mathrm{SiO}_{2}, \beta-\mathrm{Al}_{2} \mathrm{O}_{3}$ ) can be leached firstly to form pores during the leaching process. The pores formed in the aforementioned two stages increase the contact area of the cores and leaching solution, thus improving the leaching rate. In the current study, the additive amount of the preformed-pore agent was optimized, and the effect of the easy-to-corrode phases on the comprehensive properties of the cores was then compared. Based on this, the corresponding model was established.
\end{abstract}

Wei-Jun Zhu

wjzhu@xjtu.edu.cn

1 School of Mechanical Engineering and Automation, Beihang University, Beijing 100191, People's Republic of China

2 State Key Laboratory for Manufacturing Systems Engineering, Xi' an Jiaotong University, Xi' an 710049, People's Republic of China

3 School of Aeronautical Engineering, Zhengzhou University of Aeronautics, Zhengzhou 450046, People's Republic of China
Keywords Alumina-based ceramic core · Leaching · Alkali solution - Additive manufacturing (AM) . Stereolithography

\section{Introduction}

Currently, directional column- and single-crystal hollow turbine blades for aero engines use ceramic cores with high performance (e.g., silica, alumina). Because of their high chemical stability and good mechanical properties at high temperatures, alumina-based ceramic cores are commonly used in specific fields [1-3]. Traditionally, fabrication of the ceramic cores involves time-consuming procedures and low processing flexibility. The preparation of integral ceramic molds based on additive manufacturing (AM) technology provides a new method for fabricating ceramic cores with complex cooling channels efficiently [4]. Removing alumina-based ceramic cores, as represented by chemical leaching, is the key process after casting. However, high chemical stability makes the removal of cores particularly difficult. However, as the complexity of the structure increases and the strength of the material improves, the leaching process of the AM-based cores becomes more difficult [5]. One method to improve the chemical reaction is by selecting superior leaching solutions. Some types of effective leaching solutions indeed exist (i.e., hydrofluoric acid), which can concert $\mathrm{Al}_{2} \mathrm{O}_{3}$ into soluble $\mathrm{Al}^{3+}$ to remove alumina-based ceramic cores efficiently [6]. The basis reaction equation is $\mathrm{Li}_{3} \mathrm{AlF}_{6}$ $+2 \mathrm{Al}_{2} \mathrm{O}_{3}=3 \mathrm{LiAlO}_{2}+2 \mathrm{AlF}_{3}$. However, the $\mathrm{F}^{-}$ion has severely harmful effects on the human body and environment. Therefore, this method has been abandoned for many years [7]. Alkali-boiling leaching is now a commonly used method. The main research direction is now divided into 
two categories. One is to increase the leaching pressure, thereby increasing the temperature of the alkali solution and thus the reaction reactivity. High pressure can result in increased depth of the alkali solution into the cores, thereby increasing the contact area of the alkali solution and the cores [8-10]. The other research direction focuses on improving the pore structure by adding pore-forming agents to the cores to prefabricate pores, or by adding materials that will convert to easy-to-corrode phases, which can be dissolved in advance in the process of leaching to form pores, thus increasing the contact area of the alkali solution and the cores.

For the method of improving leaching pressure, significantly improving the equipment is necessary. The existence of high pressure typically requires equipment of a high standard, which often poses safety hazards. On the contrary, the method of introducing the pore structure is more efficient. This method can help to improve the porosity of the cores before and during the process of leaching, thus increase the contact area between the cores and leaching liquid. Still, the ceramic cores must meet the synthesis requirements of high-temperature strength, deflection, sintering shrinkage rate, and so on. Thus, this research represents a comprehensive optimization under a multi-objective constraint. In theory, the higher the porosity, the higher the leaching rate. However, the sintering shrinkage rate is bound to rise, and the high-temperature performance should deteriorate. Therefore, conducting systematic research on the pore-forming methods without considerably affecting other properties is necessary.

Therefore, in this study, different pore-forming methods are tested systematically. In addition, a compound method of pore-forming is introduced, which involves adding an easy combustible material to achieve preformed pores while also adding materials to the cores that convert to easy corrosion phases that can be removed prior to the process of leaching; this is likely to increase the porosity considerably. This method will likely achieve maximum porosity during leaching without affecting other properties, thus achieving a higher leaching rate.

In this study, the leaching rate of alumina-based ceramic cores is improved without affecting other properties. This is the basis for the study of the cores and promotes the technology of precision casting of hollow turbine blades $[11,12]$.

\section{Materials and methods}

\subsection{Raw materials}

Alumina-based ceramic core samples were shaped using gelcasting technology $[4,13,14]$. A ceramic slurry with a $\varphi=60 \%$ solid content was prepared according to the gradations listed in Table 1, and the fused alumina was used in a technically pure form. The as-shaped ceramic core's green body was further treated through freeze drying [15-17], high-temperature sintering, and a dipping processing [18]. The freeze-drying process was conducted in a DTY-1SL vacuum freeze dryer. Then, the core samples sized $(60 \mathrm{~mm} \times 10 \mathrm{~mm} \times 4 \mathrm{~mm})$ were subjected to a rebaking treatment at $1500{ }^{\circ} \mathrm{C}$ for $0.5 \mathrm{~h}$ to model the pouring condition during a real investment casting. Through this treatment, the core samples could be used for the etching experiment.

The material used to preform pores was a carbon fiber that was easy to burn with a diameter of approximately $7-10 \mu \mathrm{m}$ and an average length of approximately $500 \mu \mathrm{m}$. The materials that can convert to easy-to-corrode phases included $\mathrm{CaCO}_{3}, \beta-\mathrm{Al}_{2} \mathrm{O}_{3}$, and $\mathrm{SiO}_{2}$ powders. The mean particle sizes of the $\mathrm{CaCO}_{3}, \beta-\mathrm{Al}_{2} \mathrm{O}_{3}$, and $\mathrm{SiO}_{2}$ powders were $5 \mu \mathrm{m}, 5 \mu \mathrm{m}$, and $40 \mu \mathrm{m}$, respectively. The carbon fiber was mixed with the ceramic slurry at $w=1 \%, 2 \%$ and $3 \%$, respectively, of the total mass, and the corresponding mass of the alumina powder was deducted from the $40 \mu \mathrm{m}$ series. The $\mathrm{CaCO}_{3}$ powder was mixed with the ceramic slurry at $w=2 \%, 4 \%, 6 \%$ and $8 \%$, respectively, of the total mass, and the corresponding mass of the alumina powder was deducted from the $5 \mu \mathrm{m}$ series. The $\beta-\mathrm{Al}_{2} \mathrm{O}_{3}$ powder was mixed with the ceramic slurry at $w=1 \%, 2 \%, 3 \%$ and $4 \%$, respectively, of the total mass, and the corresponding mass of the alumina powder was deducted from the $5 \mu \mathrm{m}$ series. The $\mathrm{SiO}_{2}$ powder was mixed with the ceramic slurry at $w=1 \%, 2 \%, 3 \%$ and $4 \%$, respectively, of the total mass, and the corresponding mass of the alumina powder was deducted from the $40 \mu \mathrm{m}$ series.

Table 1 Particle gradation of the alumina-based ceramic slurry for gelcasting

\begin{tabular}{ll}
\hline Size/ $\mu \mathrm{m}$ & $\varphi($ Solid content $) / \%$ \\
\hline 100 & 20 \\
40 & 40 \\
5 & 15 \\
2 & 25 \\
\hline
\end{tabular}




\subsection{Sampling preparation}

Previous studies conducted by our group developed an AM-based method to fabricate ceramic cores [3, 4, 14], and the procedure for this is shown in Fig. 1. Directly driven by CAD digital data, the mold of the turbine is formed by stereolithography (SL), which is one of the AM processes, and the ceramic slurry is formed by the gelcasting method. After freeze drying, the ceramic core is formed by hightemperature sintering. The hollow blade can be cast using the strengthened ceramic core (see Fig. 1).

First, the resin molds for the test samples were prepared using an AM apparatus (SPS600B, Xi' an Jiaotong University, Xi' an, China) with a photosensitive resin (SPR 8981, Zhengbang Technology Co., Ltd., Zhuhai, China). A ceramic slurry with a low viscosity (less than $1 \mathrm{~Pa} \cdot \mathrm{s}$ ) and high solid loading $(\varphi=60 \%)$ was prepared by ball-milling for $40 \mathrm{~min}$. After degassing for $5 \mathrm{~min}$, the ceramic slurry was poured into the resin mold and then polymerized in situ to form wet green bodies under the action of the initiator and catalyst. After freeze drying for $24 \mathrm{~h}$, the dried green bodies were placed in a furnace, heated to $1100{ }^{\circ} \mathrm{C}$, and maintained at that temperature for $3 \mathrm{~h}$ to pyrolyze the resin prototype and organic monomer polymers. Finally, to promote mullitization, the samples were sintered at $1400{ }^{\circ} \mathrm{C}$ for $3 \mathrm{~h}$.

\subsection{Leaching process}

During the removal process, the ceramic core samples were immersed in the $w=70 \% \mathrm{KOH}$ solution [5]. The etching experiment was conducted in an atmospheric Monel kettle at a constant temperature of $220^{\circ} \mathrm{C}$.

A series of experiments were performed to investigate the relationships between the leaching rate and poreforming methods. In addition, the open porosity, sintering shrinkage rate, high-temperature strength, and high-temperature deflection of the cores with pore-forming additive materials were measured and analyzed synthetically.

\subsection{Testing}

During the experiments, the open porosity of the core samples was measured by the Archimedes method, and the sintering shrinkage rate was measured by Vernier callipers. The high-temperature strength was tested at $1500{ }^{\circ} \mathrm{C}$ in an HSST-6003QP high-temperature stress-strain testing machine (Sinosteel Luoyang Institute of Refractories Research Co., Ltd., China). The high-temperature deflection was tested in a TDV-1600PC high-temperature thermal deformation testing machine (Sinosteel Luoyang Institute of Refractories Research Co., Ltd., China) using ceramic samples of a nominal size of $2 \mathrm{~mm} \times 6 \mathrm{~mm} \times$ $120 \mathrm{~mm}$. The samples were mounted on a silicon-nitride ceramic fixture whose support spacing was $100 \mathrm{~mm}$ within the chamber of the testing machine that had been heated at

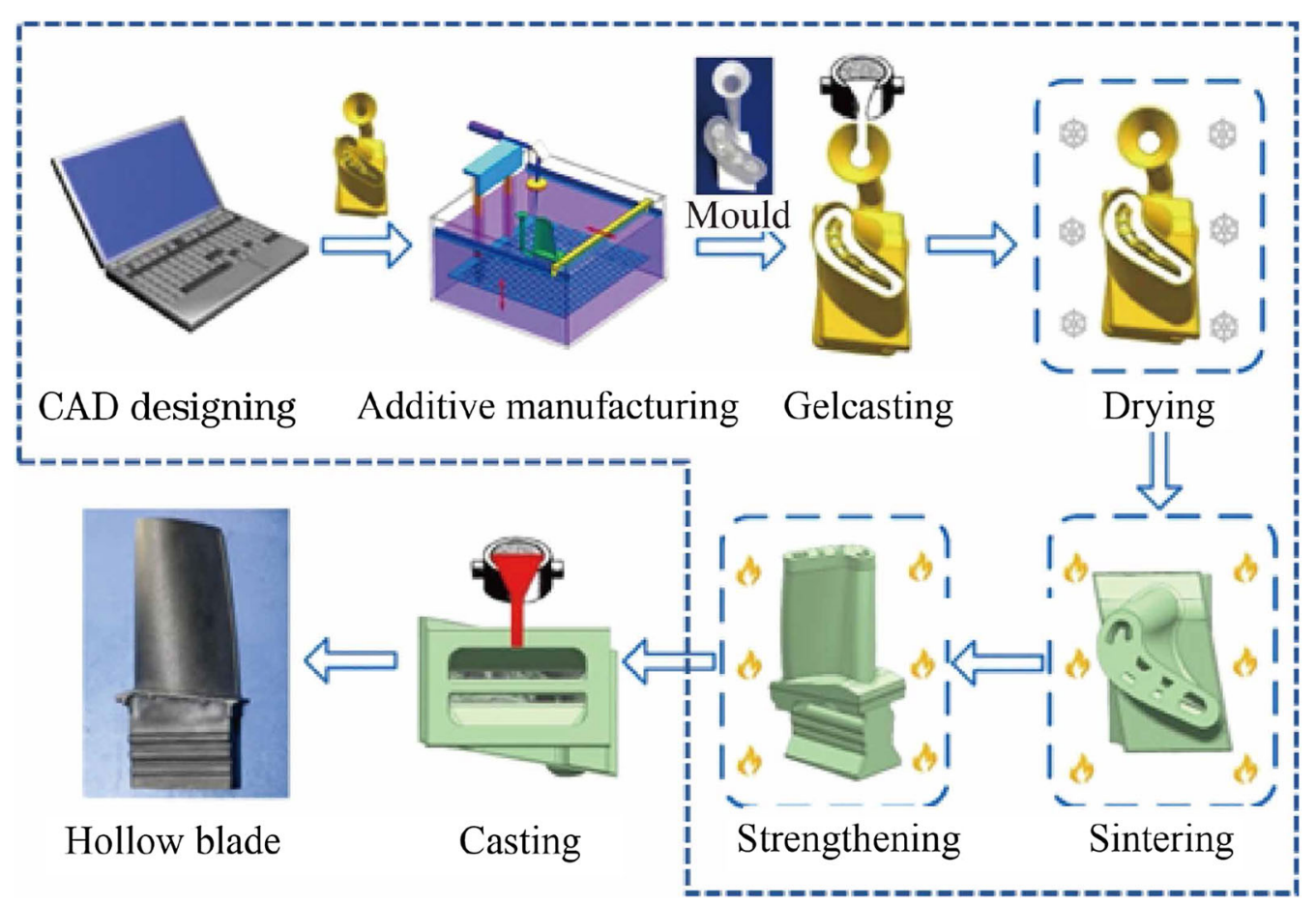

Fig. 1 Procedure of AM-based method to fabricate ceramic cores (within dotted-lined box) 
$1500{ }^{\circ} \mathrm{C}$. It was maintained for $30 \mathrm{~min}$, and then decreased to room temperature. Deflection tests were then performed by measuring the drop distance of the intermediate point of the samples. The microstructure was analyzed using scanning electron microscopy in an SU-8010 from Hitachi Ltd.

\section{Results and discussion}

\subsection{Effects of preformed pores on the performances of the cores}

The effect of the carbon fibers on the microstructures of the ceramic molds is illustrated in Fig. 2. The presence of the carbon fibers in the green bodies, as shown in Fig. 2a, led to a significant increase in the number of pores in the ceramic molds. It is worth mentioning that more open pores could be expected due to the high-aspect-ratio morphology of the carbon fibers, which would considerably enhance the leaching performance. However, the increase in porosity could possibly impair other performances of the ceramic core (e.g., the surface quality and mechanical properties). Therefore, the effects of the carbon fibers should be carefully investigated, and some trade-off must be made to balance all performances.

The results of the open porosities of the core samples with the carbon fiber additive are illustrated in Fig. 3. The open porosity of the core samples without the carbon fiber additive was $\varphi=31.3 \%$, and it increased when the carbon fiber content was increased, indicating $\varphi=34.6 \%$ for $w=3 \%$. The experimental results of the leaching rate influenced by the carbon fiber additive are illustrated in Fig. 4. The leaching rate of the core samples without the carbon fiber additive was $13.46 \% / \mathrm{h}$, and it increased along with the carbon fiber, indicating $v=18.48 \% / \mathrm{h}$ for $w=3 \%$.

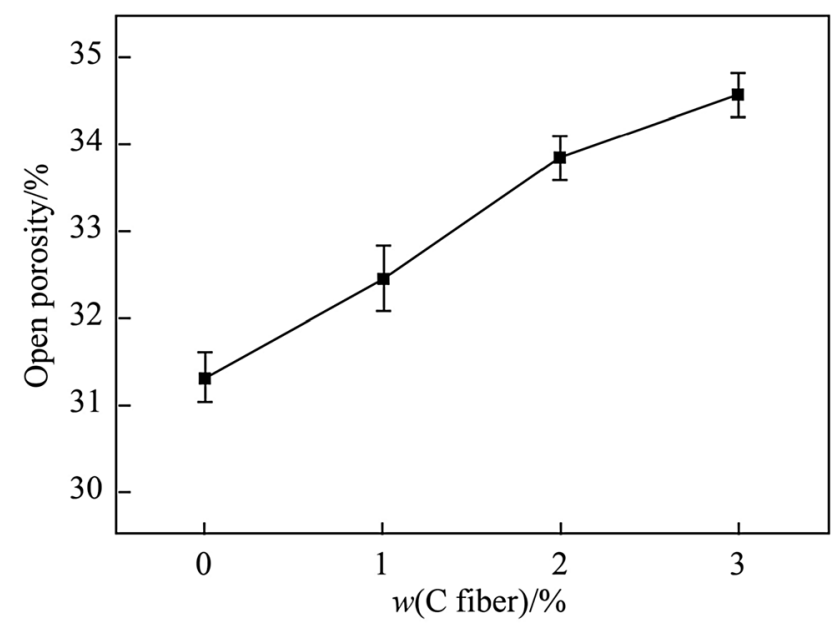

Fig. 3 Open porosities of samples with different carbon fiber additives

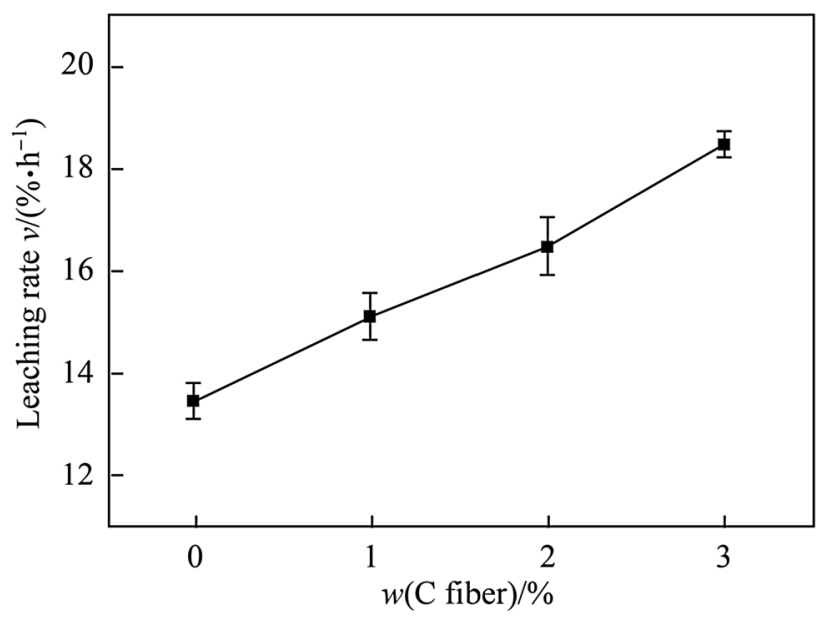

Fig. 4 Effects of carbon fiber additives on the leaching rate

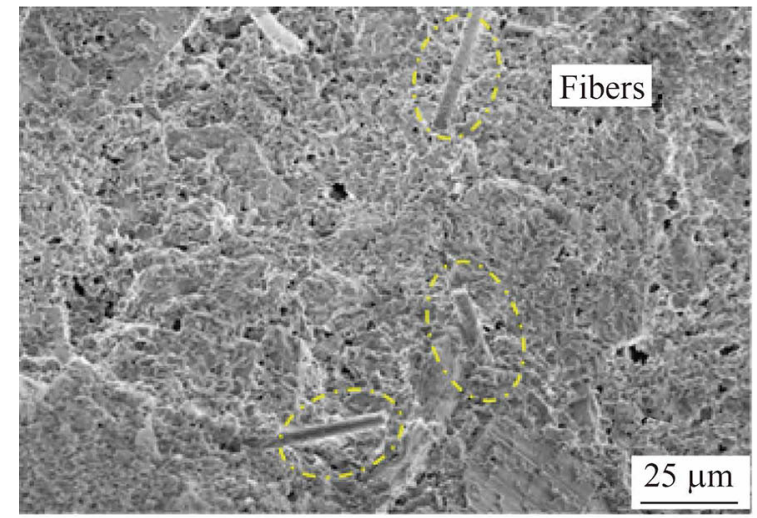

(a)

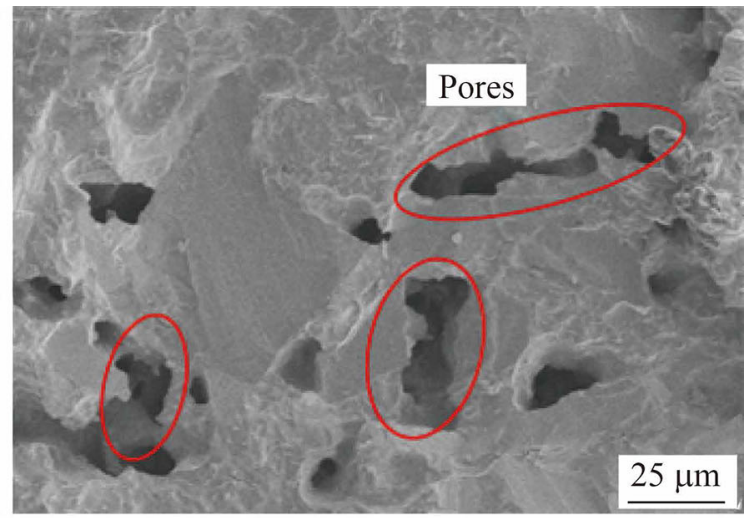

(b)

Fig. 2 Microstructures of the ceramic molds affected by the carbon fibers a carbon fibers as prepared in the green body, b pores introduced by the carbon fibers after burning out 


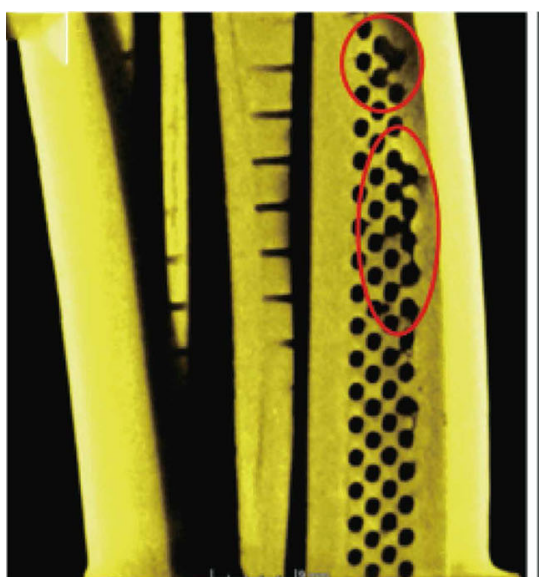

(a)

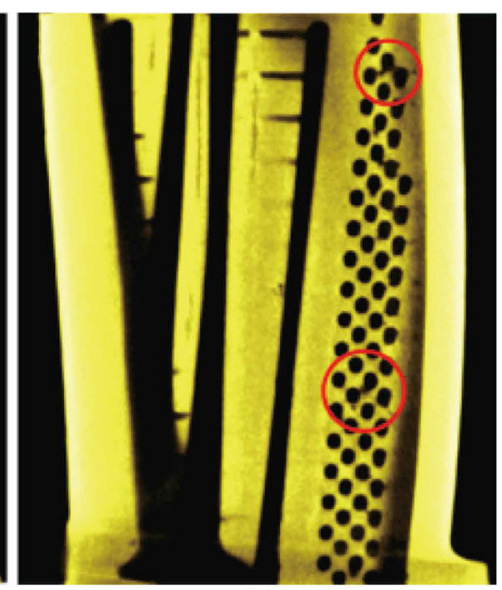

(b)

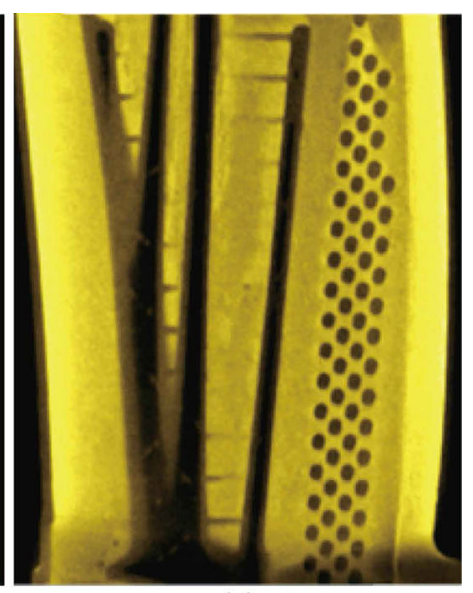

(c)

Fig. $5 \mathrm{CT}$ images of pores filling in the ceramic molds with different carbon fiber additives a $w=3 \%$, $\mathbf{b} w=2 \%$, $\mathbf{c} w=1 \%$ (circled zones indicate defects)

Table 2 Performances of the samples before and after the carbon fiber was added

\begin{tabular}{llll}
\hline $\begin{array}{l}w(\text { Carbon } \\
\text { fiber) } / \%\end{array}$ & $\begin{array}{l}\text { High-temperature } \\
\text { strength/MPa }\end{array}$ & $\begin{array}{l}\text { High-temperature } \\
\text { deflection/mm }\end{array}$ & $\begin{array}{l}\text { Sintering } \\
\text { shrinkage } \\
\text { rate/\% }\end{array}$ \\
\hline 0 & 23.8 & 0.41 & 0.13 \\
1 & 23.2 & 0.43 & 0.15 \\
\hline
\end{tabular}

With the carbon fiber additive, the viscosity of the ceramic slurry increased, which decreased the liquidity of the ceramic slurry when it was gelcasted, resulting in an insufficiently fine structure in the mold. Figure 5 shows the filling results of the tip part in the mold with different carbon fiber additives. As illustrated in Figs. 5a and b, the viscosity of the ceramic slurry is too high when the additive is $w=3 \%$ and $2 \%$, respectively, and the tip parts could not be filled, leaving obvious defects in the cores. However, when the additive was $w=1 \%$, the viscosity was moderate and the mold could be fully filled, as illustrated in Fig. 5c.

The addition of the carbon fiber can improve the leaching performance to some extent, but the increase in porosity can damage the mechanical properties. In addition, the theoretical solid phase content of the cores is reduced after the loss of the carbon fiber, and the sintering shrinkage rate increases, thus affecting the precision of the mold and blades. The other properties of the samples with $w=1 \%$ carbon fiber were tested as presented in Table 2. It can be seen that with the carbon fiber additive, the high-temperature strength was slightly lower, and the high-temperature deflection and sintering shrinkage rate increased slightly. However, these changes can be ignored. Therefore, the current study determined that the optimal additive amount of the carbon fiber was $w=1 \%$. The leaching rate increased

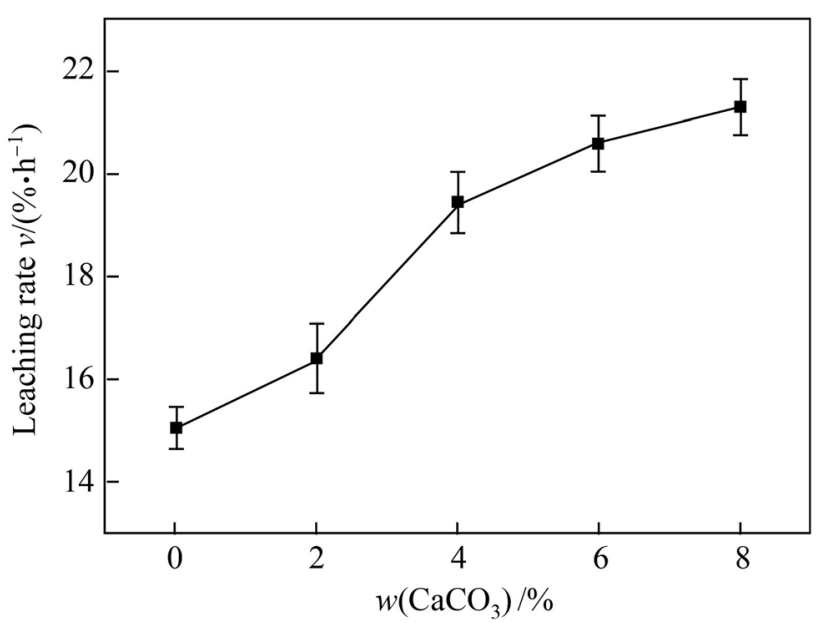

Fig. 6 Effect of the $\mathrm{CaCO}_{3}$ additive on the leaching rate

from $13.46 \% / \mathrm{h}$ to $15.05 \% / \mathrm{h}$ without affecting the moldfilling capacity of slurry and other properties.

\subsection{Effect of the compound method of pore-forming on the performances of the cores}

To increase the leaching rate further, based on $w=1 \%$ carbon fiber additive, materials that could convert to easyto-corrode phases were continuously added, which were leached prior to the process of leaching, with pores subsequently left in situ. The porosity increased further when the materials were being leached, thus the leaching rate was further improved.

\subsection{1 $\mathrm{CaCO}_{3}$ additive}

Figure 6 illustrates the influence rule of $\mathrm{CaCO}_{3}$ on the leaching rate. Figure 6 indicates that with the increase of 


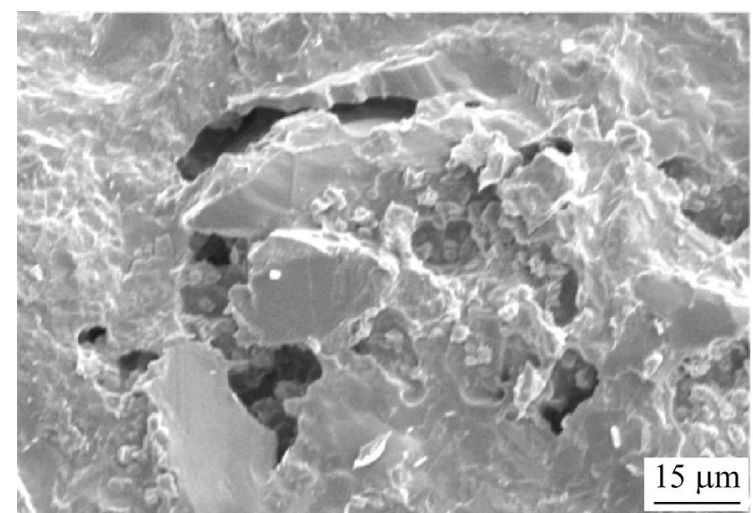

(a)

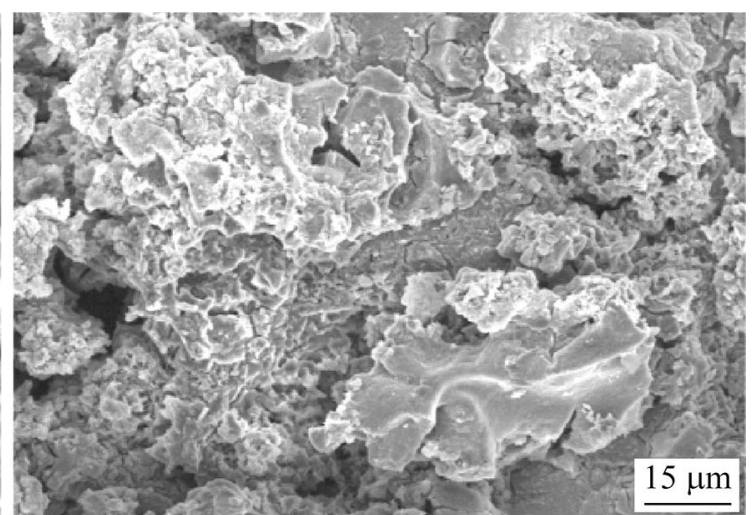

(b)

Fig. 7 Microstructures on the sample surfaces after leaching a with $w\left(\mathrm{CaCO}_{3}\right)=8 \%$, b without $\mathrm{CaCO}_{3}$ additive

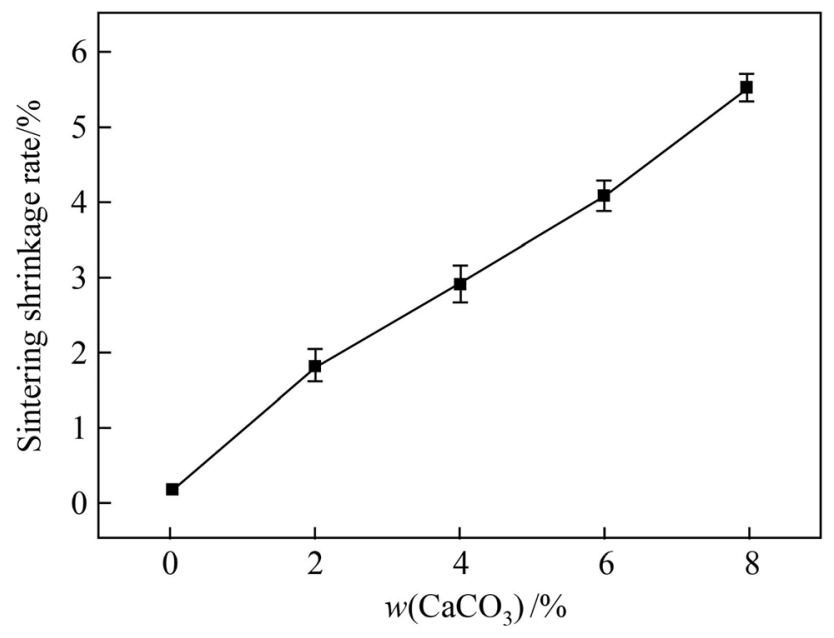

Fig. 8 Effect of the $\mathrm{CaCO}_{3}$ additive on the sintering shrinkage rate

$\mathrm{CaCO}_{3}$, the leaching rate improved. The leaching rate of the core samples without the $\mathrm{CaCO}_{3}$ additive was $15.05 \%$ / $\mathrm{h}$, and it increased when the amount of $\mathrm{CaCO}_{3}$ additive was increased, with $21.42 \% / \mathrm{h}$ for $w=8 \%$.

Figure 7 illustrates the microstructure morphologies of ceramic samples after leaching without $\mathrm{CaCO}_{3}$ and with $w=8 \% \mathrm{CaCO}_{3}$. As shown in Fig. 7, the surface break degree of the samples with $w=8 \% \mathrm{CaCO}_{3}$ additive was greater than that of the samples without $\mathrm{CaCO}_{3}$, indicating that the cores with $\mathrm{CaCO}_{3}$ could be leached more easily.

However, after $\mathrm{CaCO}_{3}$ was added, the sintering shrinkage rate of the samples significantly increased. Figure 8 illustrates the effect of $\mathrm{CaCO}_{3}$ on the sintering shrinkage rate, which increased from $0.15 \%$ to $5.59 \%$ when $w\left(\mathrm{CaCO}_{3}\right)=8 \%$ was added.

The sintering shrinkage rate increased significantly when $\mathrm{CaCO}_{3}$ was added. This was because $\mathrm{CaO}$, which was resulted from the decomposition of $\mathrm{CaCO}_{3}$, reacts with $\mathrm{Al}_{2} \mathrm{O}_{3}$ to generate calcium aluminate in the particle contact area. Calcium aluminate can be easily leached, but this

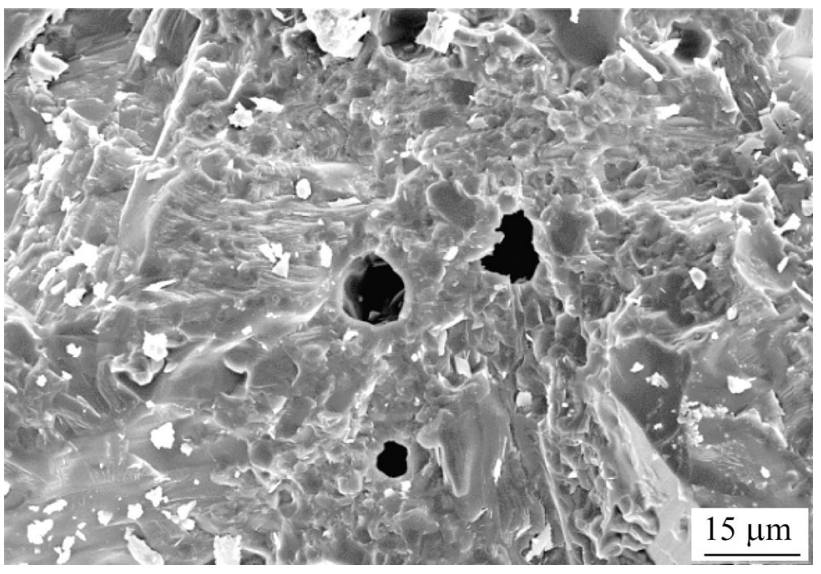

Fig. 9 Microstructure on the sample surface after sintering with $w\left(\mathrm{CaCO}_{3}\right)=8 \%$ additive

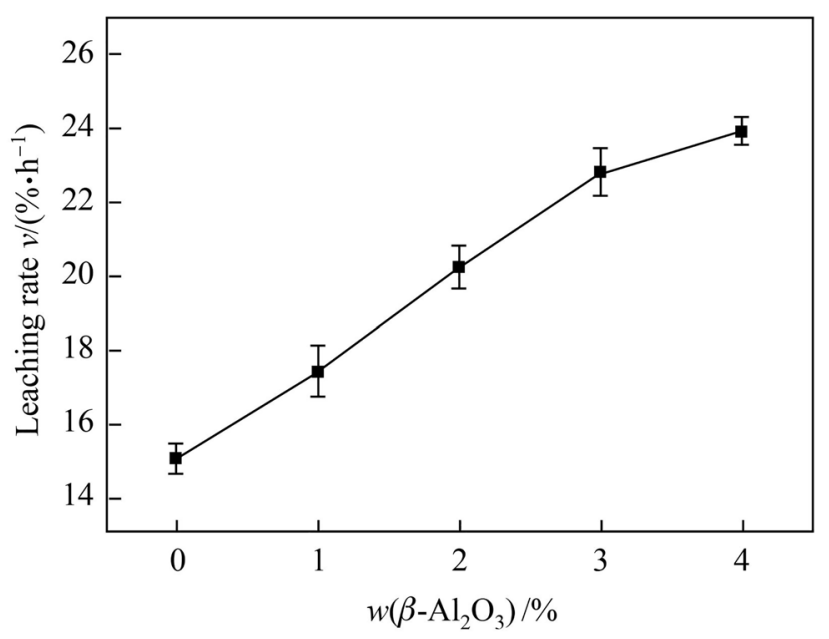

Fig. 10 Effect of the $\beta-\mathrm{Al}_{2} \mathrm{O}_{3}$ additive on the leaching rate

process involves liquid phase sintering, which causes sintering densification, thus increasing the sintering shrinkage rate. As illustrated in Fig. 9, the microstructure 


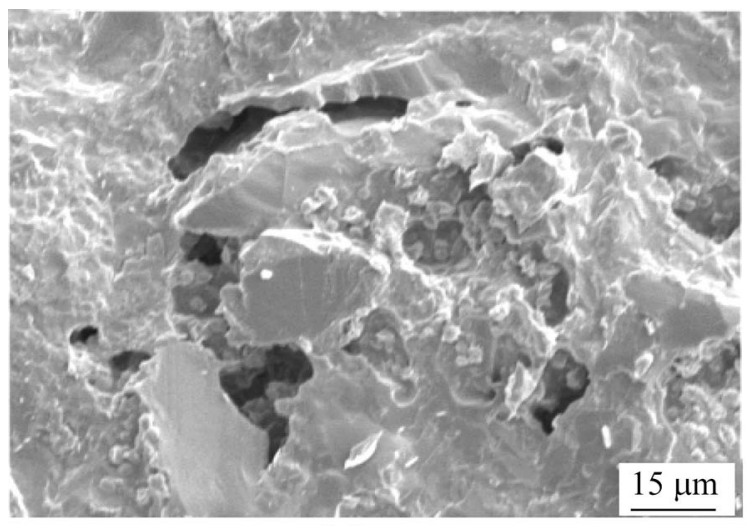

(a)

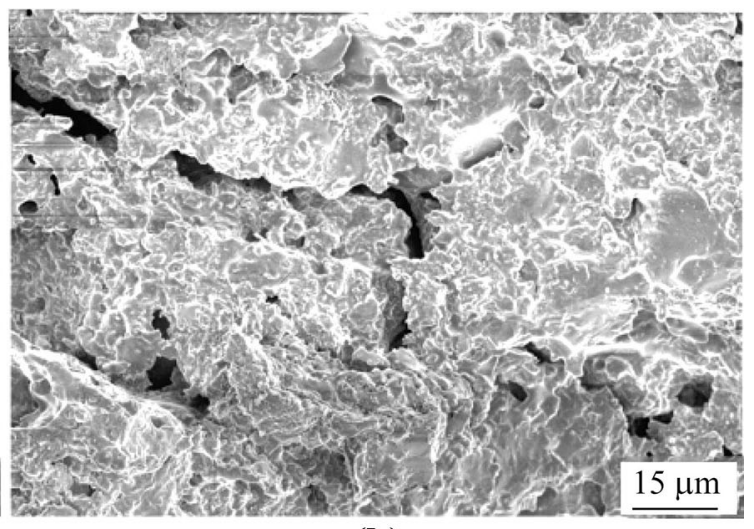

(b)

Fig. 11 Microstructures on the sample surfaces after leaching a without and b with $w\left(\beta-\mathrm{Al}_{2} \mathrm{O}_{3}\right)=1 \%$

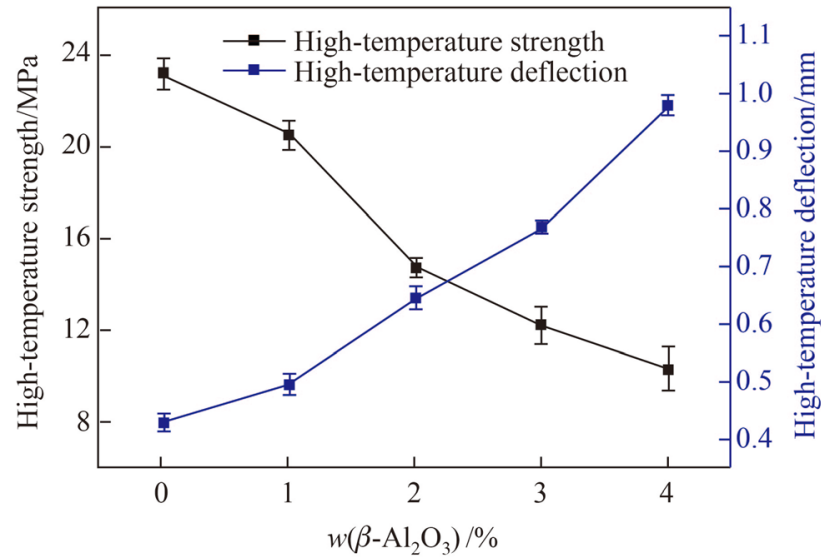

Fig. 12 Effects of the $\beta-\mathrm{Al}_{2} \mathrm{O}_{3}$ additive on the high-temperature strength and deflection

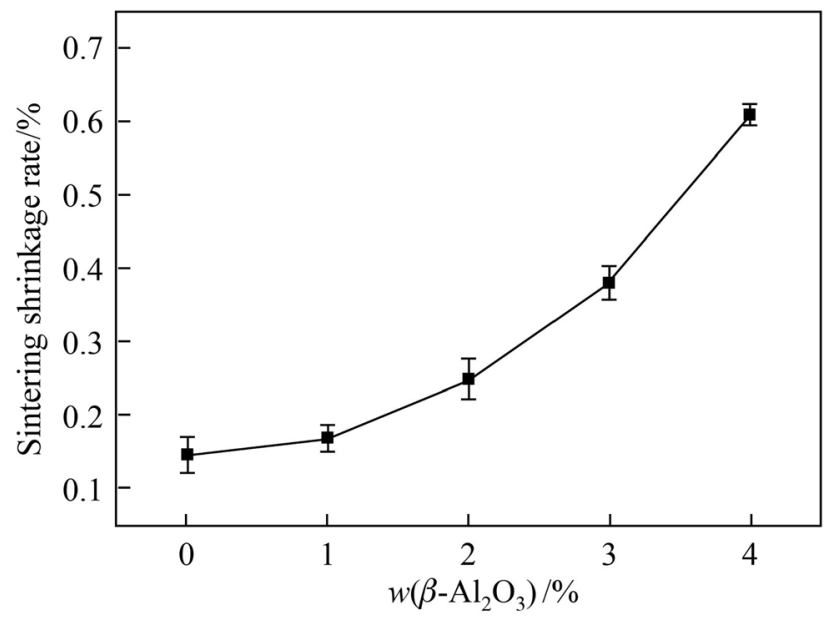

Fig. 13 Effect of the $\beta-\mathrm{Al}_{2} \mathrm{O}_{3}$ additive on the sintering shrinkage rate

morphology of the unleached sample with $w\left(\mathrm{CaCO}_{3}\right)=8 \%$ additive means that the density is very high and the porosity is very small, indicating that $\mathrm{CaCO}_{3}$ promotes densification sintering. This means that meeting the hollow

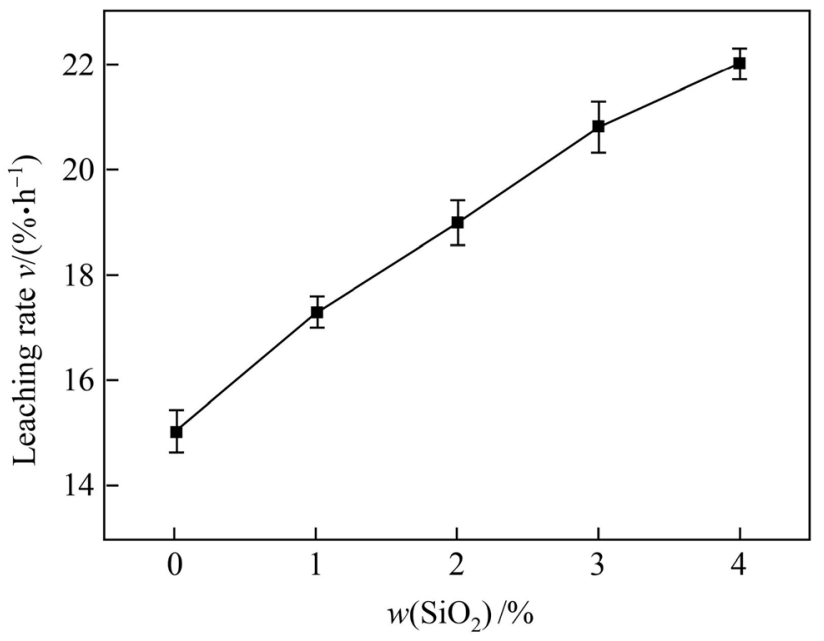

Fig. 14 Effect of the $\mathrm{SiO}_{2}$ additive on the leaching rate

turbine blade's precision casting requirements is difficult. Therefore, $\mathrm{CaCO}_{3}$ cannot be used to improve the leaching performance of ceramic cores.

\subsection{2 $\mathrm{\beta}_{-} \mathrm{Al}_{2} \mathrm{O}_{3}$ additive}

The crystal structure of $\beta-\mathrm{Al}_{2} \mathrm{O}_{3}$ is relatively loose, and the additive's density is $3.31 \mathrm{~g} / \mathrm{cm}^{3}$, which is less than the $3.97 \mathrm{~g} / \mathrm{cm}^{3}$ of $\alpha-\mathrm{Al}_{2} \mathrm{O}_{3}$. Therefore, the porosity will increase as $\beta-\mathrm{Al}_{2} \mathrm{O}_{3}$ converts to $\alpha-\mathrm{Al}_{2} \mathrm{O}_{3}$ after sintering at $1500{ }^{\circ} \mathrm{C}$. Therefore, the cores with $\beta-\mathrm{Al}_{2} \mathrm{O}_{3}$ can be easily leached.

Figure 10 illustrates the influence rule of $\beta-\mathrm{Al}_{2} \mathrm{O}_{3}$ on the leaching rate, and shows that with the increase of $\beta-\mathrm{Al}_{2} \mathrm{O}_{3}$, the leaching rate was improved. The leaching rate of the core samples without the $\beta-\mathrm{Al}_{2} \mathrm{O}_{3}$ additive was $15.05 \% / \mathrm{h}$, and it increased when the amount of $\beta-\mathrm{Al}_{2} \mathrm{O}_{3}$ additive was increased, indicating $24.01 \% / \mathrm{h}$ for $w=4 \%$.

Figure 11 illustrates the microstructure morphologies of ceramic samples after leaching without $\beta-\mathrm{Al}_{2} \mathrm{O}_{3}$ and with $w\left(\beta-\mathrm{Al}_{2} \mathrm{O}_{3}\right)=1 \%$. As shown in Fig. 11, the surface of the 


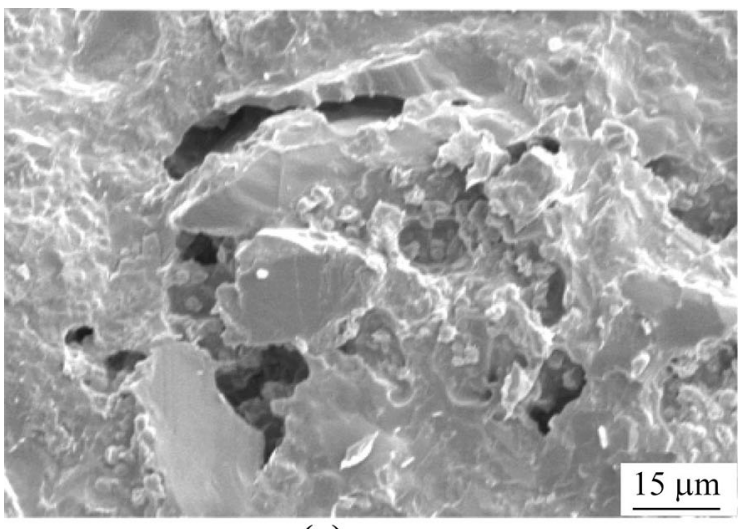

(a)

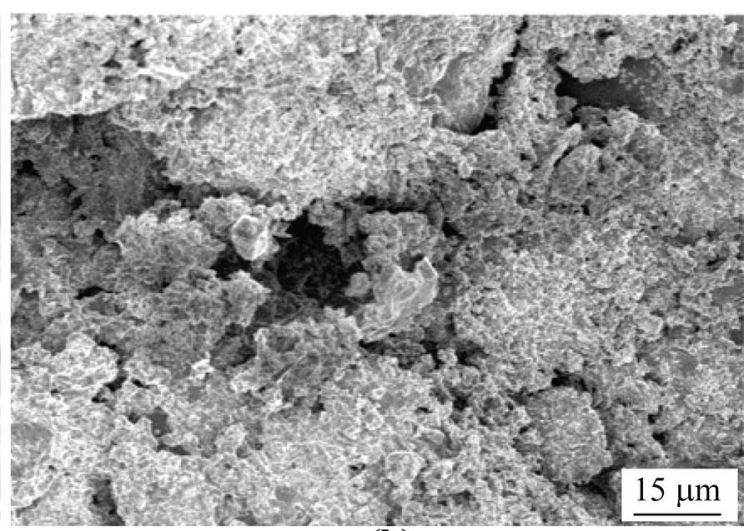

(b)

Fig. 15 Microstructures of the sample surface after leaching a without and b with $w\left(\mathrm{SiO}_{2}\right)=3 \%$

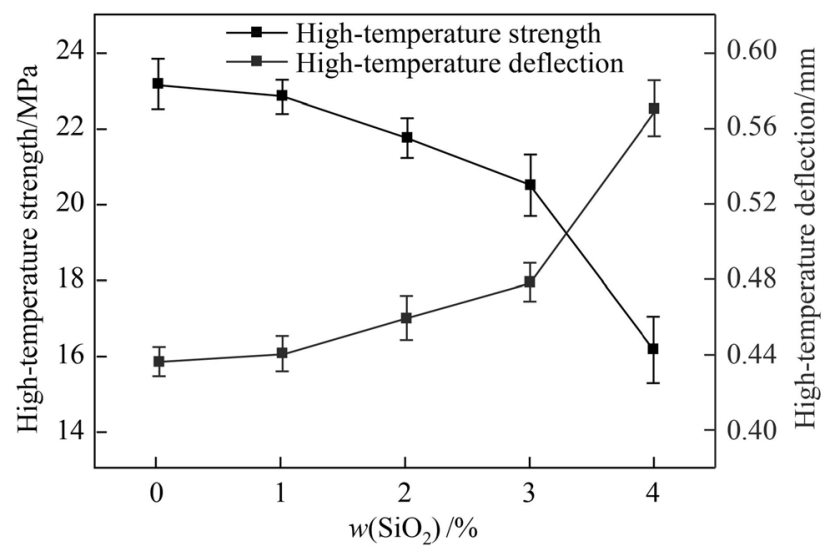

Fig. 16 Effects of the $\mathrm{SiO}_{2}$ additive on the high-temperature strength and deflection

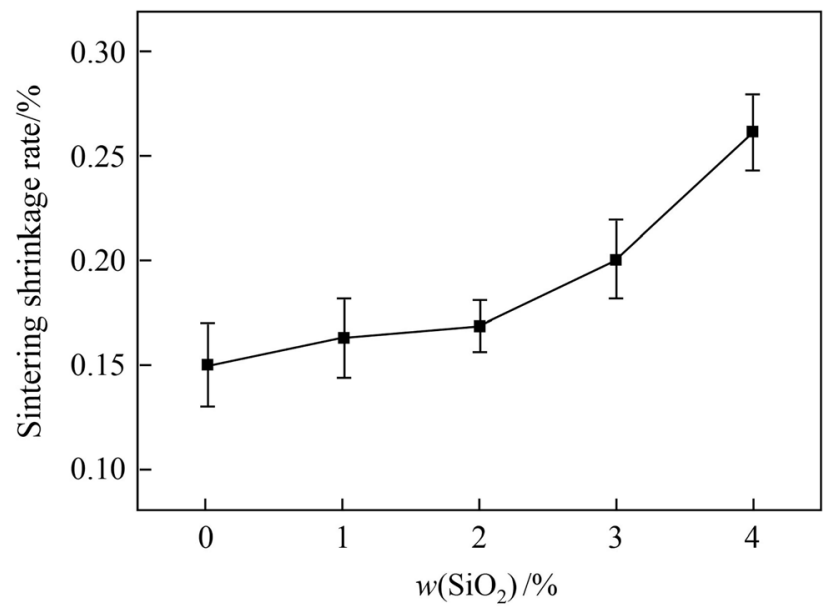

Fig. 17 Effect of the $\mathrm{SiO}_{2}$ additive on the sintering shrinkage rate

samples with $w\left(\beta-\mathrm{Al}_{2} \mathrm{O}_{3}\right)=1 \%$ additive was greater than that of the samples without $\beta-\mathrm{Al}_{2} \mathrm{O}_{3}$, indicating that the cores with $\beta-\mathrm{Al}_{2} \mathrm{O}_{3}$ could be more easily leached because the porosity was improved by having $\beta-\mathrm{Al}_{2} \mathrm{O}_{3}$ leached in the early stage of the leaching process.
Figures 12 and 13 illustrate the influence rules of $\beta$ $\mathrm{Al}_{2} \mathrm{O}_{3}$ on the high-temperature strength, high-temperature deflection, and sintering shrinkage rate. With the addition of $\beta-\mathrm{Al}_{2} \mathrm{O}_{3}$, the high-temperature strength decreased, and the high-temperature deflection and sintering shrinkage rate increased. When the mass fraction of $\beta-\mathrm{Al}_{2} \mathrm{O}_{3}$ additive increased to $2 \%$, the high-temperature strength decreased considerably, and the deflection increased rapidly. However, when the mass fraction of $\beta-\mathrm{Al}_{2} \mathrm{O}_{3}$ additive was $1 \%$, the leaching rate reached $17.46 \% / \mathrm{h}$, and the high-temperature strength, deflection, and sintering shrinkage rate were $20.89 \mathrm{MPa}, 0.47 \mathrm{~mm}$ and $0.17 \%$, respectively, which met the hollow turbine blade's precision casting requirements.

\subsection{3 $\mathrm{SiO}_{2}$ additive}

Figure 14 illustrates the influence rule of $\mathrm{SiO}_{2}$ on the leaching rate. Figure 14 indicates that the leaching rate of the core samples without the $\mathrm{SiO}_{2}$ additive was $15.05 \% / \mathrm{h}$, and it increased when the amount of the $\mathrm{SiO}_{2}$ additive was increased, indicating $22.04 \% / \mathrm{h}$ for $w=4 \%$.

Figure 15 illustrates the microstructure morphologies of ceramic samples after leaching without $\mathrm{SiO}_{2}$ and with $w\left(\mathrm{SiO}_{2}\right)=3 \%$. As shown in Fig. 15, the surface of the samples with $w\left(\mathrm{SiO}_{2}\right)=3 \%$ additive was greater than that of the samples without $\mathrm{SiO}_{2}$, indicating that the cores with $\mathrm{SiO}_{2}$ could be more easily leached because the porosity was improved when $\mathrm{SiO}_{2}$ was leached in the early stage of the leaching process.

Figures 16 and 17 illustrate the influence rules of $\mathrm{SiO}_{2}$ on the high-temperature strength, high-temperature deflection, and sintering shrinkage rate. With the addition of $\mathrm{SiO}_{2}$, the high-temperature strength decreased, and the high-temperature deflection and sintering shrinkage rate increased. When the mass fraction of $\mathrm{SiO}_{2}$ additive increased to $4 \%$, the high-temperature strength decreased significantly, and the deflection increased rapidly. The 


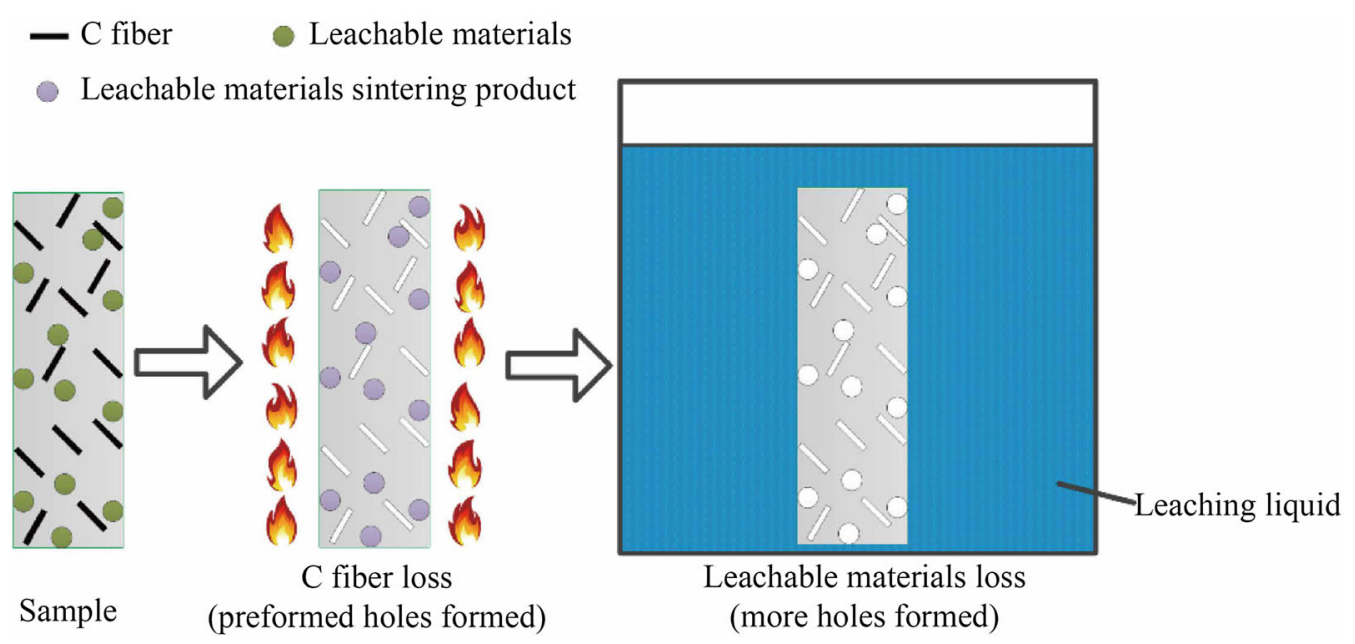

Fig. 18 Schematic of the increase of the leaching rate by the compound pore-forming method

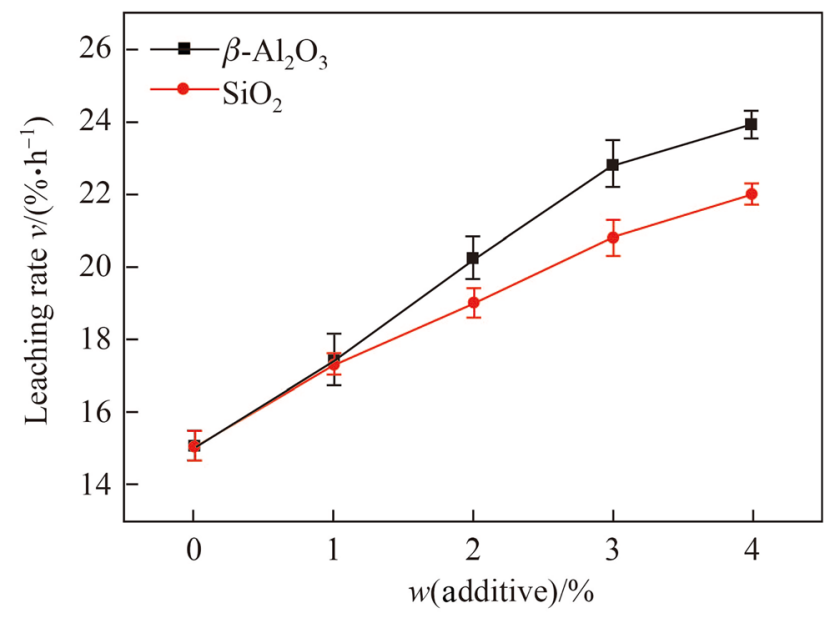

Fig. 19 Effects of $\beta-\mathrm{Al}_{2} \mathrm{O}_{3}$ and $\mathrm{SiO}_{2}$ additives on the leaching rate

reason for this is that the presence of a few low-meltingpoint phases in $\mathrm{SiO}_{2}$ can help to reduce the high-temperature strength, accelerate the creep, and promote the sintering, leading to an increased sintering shrinkage rate. Simultaneously, $\mathrm{SiO}_{2}$ transformed into cristobalite during the sintering process [19], which severely shrank when cooled to $180-270{ }^{\circ} \mathrm{C}$. The shrinkage could easily produce microcracks, thus damaging the high-temperature strength and improving the sintering shrinkage rate. However, when the mass fraction of $\mathrm{SiO}_{2}$ additive was $3 \%$, the leaching rate reached $20.92 \% / \mathrm{h}$, and the hightemperature strength, deflection, and sintering shrinkage rate were $20.60 \mathrm{MPa}, 0.48 \mathrm{~mm}$ and $0.20 \%$, respectively, which met the hollow turbine blade's precision casting requirements.

\subsection{Mechanism of pore-forming methods to improve leaching performance}

In theory, the higher the porosity, the larger is the contact area between the leaching liquid and the cores and the higher is the leaching rate. Based on the $w(\mathrm{C}$ fiber $)=1 \%$, adding materials that can convert to easy-to-corrode phases can improve the leaching performance of the cores. This is because the compound pore-forming method can achieve preformed pores prior to the leaching. In addition, the easy corrosion phases are leached in advance, and thus more pores are generated, thus increasing the leaching rate.

The principles behind the process are illustrated in Fig. 18. In a typical condition, combining the two mechanisms, such as performed pores and easy-to-corrode phases, improve the leaching performance. For the former, carbon fibers are used as the additives and open pores are produced by burning out carbon fibers during sintering. For the latter, more pores are introduced by eroding the easyto-corrode phases, such as $\mathrm{CaCO}_{3}, \beta-\mathrm{Al}_{2} \mathrm{O}_{3}$, and $\mathrm{SiO}_{2}$.

The chemical reaction during the process is

$2 \mathrm{KOH}+\mathrm{Al}_{2} \mathrm{O}_{3}=2 \mathrm{KAlO}_{2}+\mathrm{H}_{2} \mathrm{O}$.

The removal efficiency is described quantitatively as the leaching rate by measuring the dry weights before and after the removal process, and the leaching rate $(v)$ is calculated by the following equation

$v=\frac{m_{1}-m_{2}}{m_{1} \times t} \times 100 \%$,

where $m_{1}$ and $m_{2}$ are the weights of the core samples before and after the leaching process, respectively, and $t$ is the etching time. 
Table 3 Performances of alumina samples with different additives

\begin{tabular}{|c|c|c|c|c|}
\hline \multirow[t]{2}{*}{ Samples } & \multicolumn{4}{|l|}{ Performances } \\
\hline & $\begin{array}{l}\text { Sintering shrinkage } \\
\text { rate/\% }\end{array}$ & $\begin{array}{l}\text { High-temperature } \\
\text { strength/MPa }\end{array}$ & $\begin{array}{l}\text { High-temperature } \\
\text { deflection/mm }\end{array}$ & $\begin{array}{l}\text { Leaching } \\
\text { rate } /\left(\% \cdot \mathrm{h}^{-1}\right)\end{array}$ \\
\hline$\alpha-\mathrm{Al}_{2} \mathrm{O}_{3}$ & 0.13 & 23.80 & 0.41 & 13.46 \\
\hline$\alpha-\mathrm{Al}_{2} \mathrm{O}_{3}+\mathrm{C}(w=1 \%)$ & 0.15 & 23.20 & 0.43 & 15.05 \\
\hline$\alpha-\mathrm{Al}_{2} \mathrm{O}_{3}+\mathrm{C}(w=1 \%)+\mathrm{CaCO}_{3}$ & Too high & - & - & - \\
\hline$\alpha-\mathrm{Al}_{2} \mathrm{O}_{3}+\mathrm{C}(w=1 \%)+\beta-\mathrm{Al}_{2} \mathrm{O}_{3}(w=1 \%)$ & 0.17 & 20.89 & 0.47 & 17.46 \\
\hline$\alpha-\mathrm{Al}_{2} \mathrm{O}_{3}+\mathrm{C}(w=1 \%)+\mathrm{SiO}_{2}(w=3 \%)$ & 0.20 & 20.60 & 0.48 & 20.92 \\
\hline
\end{tabular}

\subsection{Comparison of leaching performances with different pore-forming methods}

A comparison of the effects of $\beta-\mathrm{Al}_{2} \mathrm{O}_{3}$ and $\mathrm{SiO}_{2}$ additives on the leaching rate is illustrated in Fig. 19. A comparison of comprehensive performances of the different samples is presented in Table 3 .

\section{Conclusions}

The effects of different pore-forming methods on the leaching rates of alumina-based ceramic cores was studied, and the effects of different pore-forming methods on the other properties of the cores was discussed. The addition of carbon fiber increased the porosity of cores, thus improving the leaching performance. When the amount of added carbon fiber was $w=1 \%$, the porosity and leaching rate increased to $32.4 \%$ and $15.05 \% / \mathrm{h}$, respectively, whereas other performances (e.g., filling capacity and mechanical properties) were maintained. $\mathrm{CaCO}_{3}$ could improve the leaching performance, but it resulted in an extremely high sintering shrinkage rate. $\beta-\mathrm{Al}_{2} \mathrm{O}_{3}$ and $\mathrm{SiO}_{2}$ increased the porosity, thus improving the leaching performance. When the mass fraction of added $\beta-\mathrm{Al}_{2} \mathrm{O}_{3}$ and $\mathrm{SiO}_{2}$ were $1 \%$ and $3 \%$, respectively, the leaching rate increased to $17.46 \% / \mathrm{h}$ and $20.92 \% / \mathrm{h}$, respectively, without hampering other properties. As previously mentioned, carbon fiber, $\mathrm{CaCO}_{3}$, $\beta-\mathrm{Al}_{2} \mathrm{O}_{3}$, and $\mathrm{SiO}_{2}$ are all additives that improve the leaching performance of $\alpha-\mathrm{Al}_{2} \mathrm{O}_{3}$-based ceramic cores. However, the mechanisms of improvement are different. Carbon fibers are used to preform pores (open pores in the case), whereas $\mathrm{CaCO}_{3}, \beta-\mathrm{Al}_{2} \mathrm{O}_{3}$, and $\mathrm{SiO}_{2}$ are based on introducing easy-to-corrode phases into the $\alpha-\mathrm{Al}_{2} \mathrm{O}_{3}$ matrix. In this study, the effect of every additive was discussed, and combinations of additives were also investigated by mixing carbon fibers with $\mathrm{CaCO}_{3}, \beta-\mathrm{Al}_{2} \mathrm{O}_{3}$, and $\mathrm{SiO}_{2}$ additive. However, combining two additives of the same mechanism (e.g., $\mathrm{CaCO}_{3}$ with $\beta-\mathrm{Al}_{2} \mathrm{O}_{3}, \beta-\mathrm{Al}_{2} \mathrm{O}_{3}$ with $\mathrm{SiO}_{2}$ ) was not conducted in this study. With an increase in the number of design variables, further improvement of the leaching performance could be expected by optimizing the formula of the two additives of the same mechanism. Further studies are recommended to investigate the effects of combining different additives on the leaching performances of ceramic cores.

Acknowledgements This work was supported by the National Natural Science Foundation of China (Grant No. 51505457), the National Science and Technology Major Project (Grant No. 2017-VII-00080101), the Key Research and Development Program of Shaanxi Province (Grant No. 2018ZDXM-GY-059), the Open Fund of State Key Laboratory of Manufacturing Systems Engineering (Grant No. SKLMS2016013), the Fundamental Research Funds for the Central Universities, and the Youth Innovation Team of Shaanxi Universities.

Open Access This article is distributed under the terms of the Creative Commons Attribution 4.0 International License (http://crea tivecommons.org/licenses/by/4.0/), which permits unrestricted use, distribution, and reproduction in any medium, provided you give appropriate credit to the original author(s) and the source, provide a link to the Creative Commons license, and indicate if changes were made.

\section{References}

1. Najjar YSH, Alghamdi AS, Al-Beirutty MH (2004) Comparative performance of combined gas turbine systems under three different blade cooling schemes. Appl Therm Eng 24(13): 1919-1934

2. Shi X, Agnew B, Che D (2010) Performance enhancement of conventional combined cycle power plant by inlet air cooling, inter-cooling and LNG cold energy utilization. Appl Therm Eng 30(14-15):2003-2010

3. Lu ZL, Cao JW, Jing H et al (2013) Review of main manufacturing processes of complex hollow turbine blades. Virtual Phys Prototyp 8(2):87-95

4. Wu H, Li D, Tang Y et al (2010) Rapid fabrication of aluminabased ceramic cores for gas turbine blades by stereolithography and gelcasting. J Mater Process Technol 209(18-19):5886-5891

5. Zhang H, Lu ZL, Zhe JI et al (2017) Basis for the alkaline removal process design of the alumina-based ceramic core. J Ceram Soc Jpn 125:616-622

6. Arendt RH, Borom MP, Huseby IC et al (1978) Molten salt leach for removal of inorganic cores from directionally solidified eutectic alloy structures. General Electric Company, Boston

7. Kruglov EP, Kochetova GK (2007) Improvement of a technological process for ceramic core removal out of internal cavities 
of aircraft GTE turbine blade castings. Rus Aeronaut (Iz VUZ) 50(2):227-229

8. Parille DRSW, Earle AA (1998) Method of core leach. United States: United Technologies Corporation, Hartford

9. Sangeeta D, Niskayuna N (1998) Method of dissolving or leaching ceramic cores in airfoils. United States: General Electric Company, Schenectady

10. Schlienger MEN, Baldwin Michael D, Eugenio A (2004) Method and apparatus for removing ceramic material from cast components. United States: Rolls-Royce Corporation, Indianapolis

11. Wu HH, Li DC, Tang YP et al (2011) Improving high temperature properties of alumina based ceramic cores containing yttria by vacuum impregnating. Mater Sci Technol-lond 27(4):823-828

12. Lu Z, Tian G, Wan W et al (2016) Effect of in situ synthesised mullite whiskers on the high-temperature strength of $\mathrm{Al}_{2} \mathrm{O}_{3}$-based ceramic moulds for casting hollow turbine blades. Ceram Int 42:18851-18858

13. Tian G, Lu Z, Miao K et al (2015) Formation mechanism of cracks during the freeze drying of gelcast ceramic parts. J Am Ceram Soc 98(10):3338-3345

14. Miao K, Lu Z, Cao J et al (2016) Effect of polydimethylsiloxane on the mid-temperature strength of gelcast $\mathrm{Al}_{2} \mathrm{O}_{3}$ ceramic parts. Mater Design 89:810-814

15. Kiennemann J, Chartier T, Pagnoux C et al (2005) Drying mechanisms and stress development in aqueous alumina tape casting. J Eur Ceram Soc 25(9):1551-1564

16. Fukasawa T, Ando M, Ohji T et al (2010) Synthesis of porous ceramics with complex pore structure by freeze-dry processing. J Am Ceram Soc 84(1):230-232

17. Zhang D, Zhang Y, Xie R et al (2012) Freeze gelcasting of aqueous alumina suspensions for porous ceramics. Ceram Int 38(7):6063-6066

18. Qin Y, Pan W (2009) Effect of silica sol on the properties of alumina-based ceramic core composites. Mater Sci Eng, A 508(1-2):71-75

19. Kim YH, Yeo JG, Choi SC (2016) The effect of fused silica crystallization on flexural strength and shrinkage of ceramic cores for investment casting. J Korean Ceram Soc 53:246-252

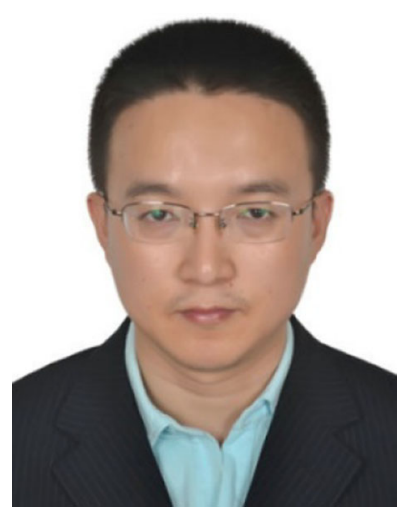

Wei-Jun Zhu received his $\mathrm{Ph} . \mathrm{D}$. degree in Mechanical Engineering from Xi'an Jiaotong University, P. R. China. He is currently an Associate Professor at Beihang University, P. R. China. His research interests include additive manufacturing technology (3D printing) and its applications in aerospace.

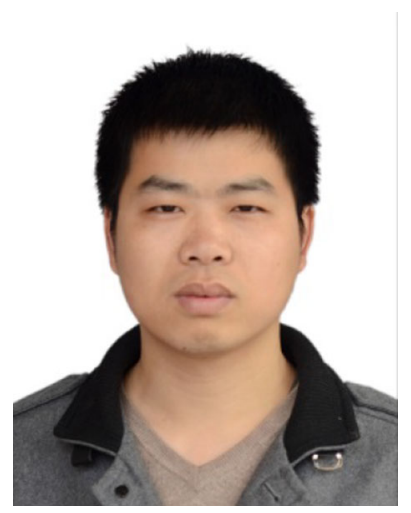

Guo-Qiang Tian received his Ph.D. degree in Mechanical Engineering from Xi'an Jiaotong University, P. R. China. He is currently a lecturer at Zhengzhou University of Aeronautics, P. R. China. His research interest is additive manufacturing technology of ceramic mold.

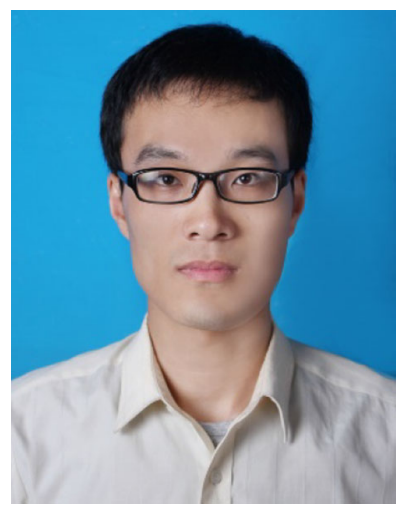

Yang Lu received his M.S. degree in Mechanical Engineering from Xi'an Jiaotong University, P. R. China. He is currently an Engineer at Tianjin infinity Industrial Technology Co., Ltd, P. R. China. His research interest is additive manufacturing technology (3D printing).

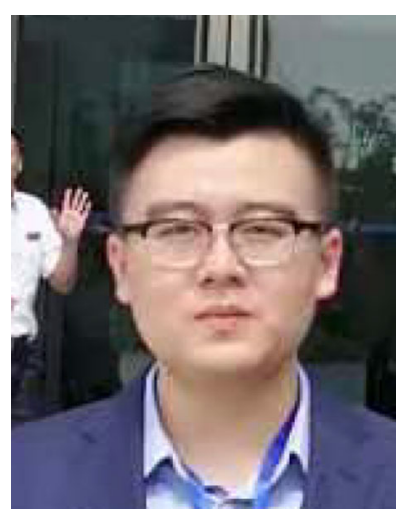

Kai Miao received his Ph.D. degree in Mechanical Engineering from Xi'an Jiaotong University, P. R. China. He is currently a Post-Doctor at Xi' an Jiaotong University, P. R. China. His research interest is additive manufacturing technology (3D printing).

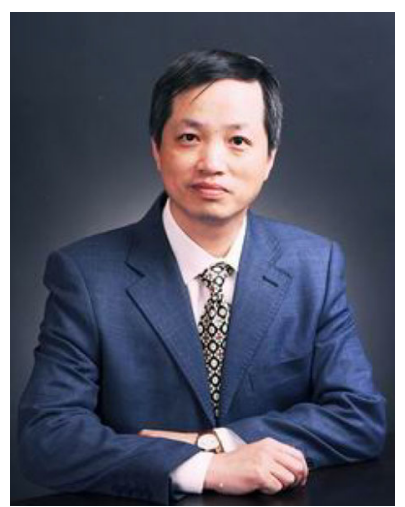

Di-Chen $\mathbf{L i}$ received his Ph.D. degree in Mechanical Engineering from $\mathrm{Xi}$ 'an Jiaotong University, P. R. China. He is currently a Professor and Director of State Key Lab for Manufacturing System Engineering at $\mathrm{Xi}$ 'an Jiaotong University, P. R. China. His research interests include additive manufacturing technology (3D printing), Bio-fabrication and Shaping of composite materials. 